\title{
Source parameters of the $2017 M_{\mathrm{w}} 6.2$ Yukon earthquake doublet inferred from coseismic GPS and ALOS-2 deformation measurements
}

\author{
Wanpeng Feng ${ }^{\oplus},{ }^{1,2}$ Sergey Samsonov, ${ }^{2}$ Cunren Liang, ${ }^{3}$ Junhua Li, ${ }^{2}$ \\ François Charbonneau, ${ }^{2}$ Chen $\mathrm{Yu}^{4}$ and Zhenhong $\mathrm{Li}^{4}$ \\ ${ }^{1}$ Guangdong Provincial Key Laboratory of Geodynamics and Geohazards, School of Earth Sciences and Engineering, Sun Yat-Sen University, Guangzhou, \\ China.E-mail: wanpeng.feng@hotmail.com \\ ${ }^{2}$ Canada Center for Mapping and Earth Observation, Natural Resources Canada, Ottawa, Canada \\ ${ }^{3}$ Division of Geological and Planetary Sciences, California Institute of Technology, Pasadena, USA \\ ${ }^{4}$ COMET, School of Engineering, Newcastle University, Newcastle upon Tyne, NE1 7R7, United Kingdom
}

Accepted 2018 November 21. Received 2018 November 11; in original form 2018 March 01

\begin{abstract}
SUMMAR Y
We investigated an $M_{\mathrm{w}} \sim 6.2$ earthquake doublet on the border of the USA and Canada using ALOS2 Light-of-Sight displacements and GPS measurements. We selected three L-band ALOS-2 interfergorams with temporal baselines of one yr to extract coseismic deformation maps, in which master and slave images were both acquired in July. A subpixel-based alignment and another range spectral splitting techniques under the GAMMA InSAR software framework were applied to improve the interferometric coherence and reduce the effects of phase anomalies in two of the three interferometric pairs due to either ionospheric delay or a potential focusing issues in the generation of the ALOS2 SLC data. The updated interferograms convincingly reveal deformation fringe patterns produced by the two earthquakes. We conducted a nonlinear geophysical inversion to estimate the geometric parameters of the earthquakes with the InSAR and GPS measurements. The best-fitting model shows that a thrust faulting on a reverse fault and left-lateral strike-slip faulting on a nearly vertical fault with the centroid depths of $9.3 \pm 0.6$ and $8.4 \pm 0.7 \mathrm{~km}$, respectively, are most likely responsible for the earthquake doublet. The eastern Denali fault (EDF) and Duke River fault are major active faults in the region and the earthquake doublet could be due to reactivation of the part of the two faults system.
\end{abstract}

Key words: Ionosphere correction; Radar interferometry; Joint inversion; Yukon earthquakes; Earthquake hazards.

\section{INTRODUCTION}

An $M_{\mathrm{w}} 6.2$ earthquake (eq. 1) struck the southern Yukon Territory and Alaska near the border of the United States and Canada at 12:31:55 (UTC), May 1 of 2017 at approximately $\left[59.821^{\circ} \mathrm{N}\right.$ $\left.136.711^{\circ} \mathrm{W}\right]$, and two hours later another $M_{\mathrm{w}} 6.2$ event (eq. 2) occurred $1.3 \mathrm{~km}$ northeast of the eq. (1) based on a preliminary earthquake report from the United States Geological Survey (USGS). He et al. (2018) estimated the source characteristics of the earthquake doublet eqs (1) and (2) using seismic and GPS data and reported that they were reverse and strike-slip faulting processes, respectively. Vigorous ground motion triggered by the earthquake doublet were felt by residents at Whitehorse, the capital of the Yukon Territory, $\sim 130 \mathrm{~km}$ northeast of the epicentres. A series of avalanches and landslides activities were observed in the field survey performed 2 months later by the Yukon Geological Survey (Steve Israel, personal communication, 2017). Due to rare inhabitants, no casualties and significant economic loss were reported except scattered damages in the vicinity of the earthquakes. Since the $2002 M_{\mathrm{w}} 7.9$ Denali earthquake, the two 2017 May earthquakes were the largest eventsin the northern Arctic region in the recent years and they have also been the largest events instrumentally recorded within the land of Canada.

The epicentres of the two events lie in a complex tectonic system between the Duke River and Eastern Denali faults (Fig. 1). Due to the close spatial relationship and consistent focal mechanisms with the local mechanical context of the Duke River fault, He et al. (2018) (hereafter referred to as 'He2018') proposed that the two events were associated with the reactivation of the Duke Rive fault. Tectonically, the local tectonic activities in the region are driven by the plate collision between the North American plate and the Pacific plate (Christeson et al. 2010). The latter is moving northwestward 


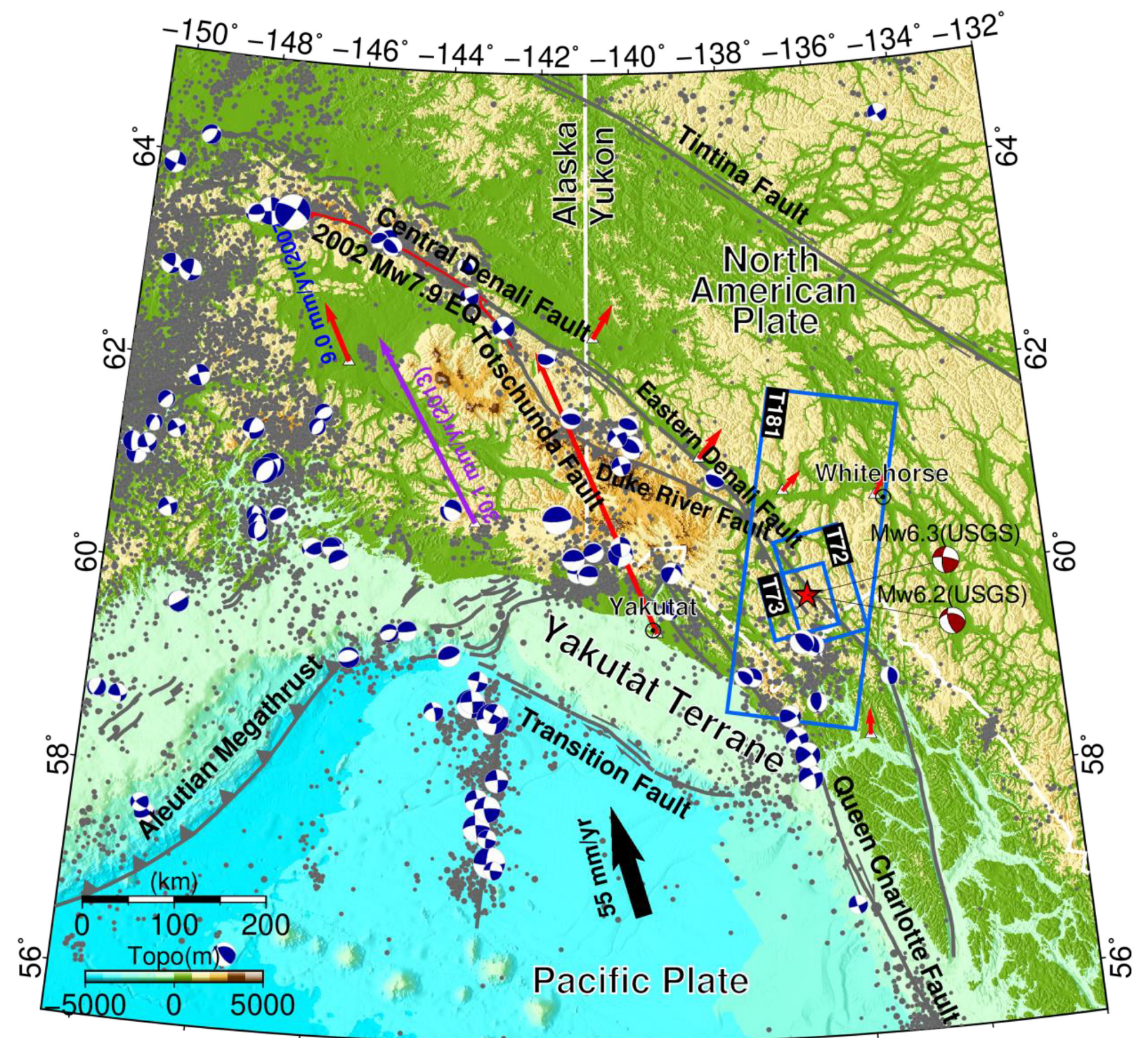

Figure 1. Tectonic background of the 2017 May 1 double earthquakes and spatial coverage of SAR data used in this study. Grey dots are historical earthquakes recorded by USGS in the region. The beach balls are based on the focal mechanisms from the global CMT catalogue (Dziewonski et al. 1981), while the red beach balls are based on the preliminary focal mechanism solutions from (https://earthquake.usgs.gov/earthquakes/search/). Three GPS velocity datasets were used to depict the plate motion direction in the study region: blue (Leonard et al. 2007), purple (Elliott et al. 2013) and thick black arrows (Lisowski et al. 1987). The shallow blue polygons in the figure are the ALOS2 SAR footprints of different tracks. The surface rupture traces of the $2002 M_{\mathrm{w}} 7.9$ Denali fault was based on Open data made by Haeussle (2009). The topography data are collected from SIO (Smith \& Sandwell 1997). The faults used in the figures are partly collected from the USGS database (https://earthquake.usgs.gov/hazards/qfaults/map/\#qfaults). The colour version of this figure is available only in the electronic edition.

at a rate of $55 \mathrm{~mm} \mathrm{yr}^{-1}$ relative to the stable North American plate (Fletcher \& Freymueller 1999; Mazzotti \& Hyndman 2002). The collision resulted in significant crustal shortening in a wide region from the Yakutat Terrane to the further north (Elliott et al. 2013, Fig. 1). Due to the fast relative movements and resulting large deformation on the boundary of the two plates, particularly the coastal areas, Alaska and its vicinity are one of the most seismically active regions in the world (Doser et al. 1997).

The tectonic strain loaded by the collision is gradually absorbed in the wide region from the Yakutat Terrane to the Canadian cordillera, $\sim 800 \mathrm{~km}$ northeast. A surface motion rate at Yakutat city decreases to only $40 \mathrm{~mm} \mathrm{yr}^{-1}$ in the identical direction (Fig. 1), while the surface movement sharply lowers to $9 \mathrm{~mm} \mathrm{yr}^{-1}$ only around $62^{\circ} \mathrm{N}$
(Fig. 1). The trends of the northwester shortening across Alaska to the central Denali fault are identical with the relative movement between the plates. The Denali fault system is one of major intracontinental structures in the Alaska-Canada cordillera, which hosted the 2002 November $M_{\mathrm{w}} 7.9$ Denali earthquake along the central Denali segment (Haeussler et al. 2004). That was the largest dextral strike-slip event ever recorded in the past five decades in the mainland of the North American Plate. A 330-km-long surface rupture was produced during the 2002 main shock (Haeussler et al. 2004; Haeussler 2009). As shown in Fig. 1, in the last $40 \mathrm{~km}$ rupture, the earthquake propagated along the Totschunda fault, other than continuously proceeding to the Eastern Denali Fault (EDF). In the contrast to an interseismic slip rate of $10 \mathrm{~mm} \mathrm{yr}^{-1}$ along the 
Central Denali fault, the Totschunda fault was believed moving at a relatively slow rate of approximately $6 \mathrm{~mm} \mathrm{yr}^{-1}$ (Matmon et al. 2006). It stretches southeastward only for $50 \mathrm{~km}$, and then turns west after connecting with the Duke River fault at approximately $61.3^{\circ} \mathrm{N}$ (Fig. 1, Snyder et al. 2005; Cobbett et al. 2017). Due to difficult access to the region and only a few large earthquakes previously recorded, investigations on the eastern Denali fault were rarely conducted before the 2017 earthquakes. Only campaign GPS interseismic velocities (Leonard et al. 2007) at few stations were made along the eastern Denali fault.

Surface motions relative to the stable American Plate in the wide area along the US-Canada border to the Yukon Territory vary as shown with the interseismic GPS velocities (Fuis et al. 2008; Christeson et al. 2010; Koons et al. 2010; Elliott et al. 2013, Fig. 1). From the Yukutat Terrance to the EDF, a northwestern surface motion (approximately $\left.\mathrm{N} 315^{\circ}\right)$ has turned to northeast $\left(\sim \mathrm{N} 45^{\circ}\right)$, nearly perpendicular to the EDF on the north side of the fault (Fig. 1). Post-seismic relaxation of the 2002 Denali earthquake along the central Denali fault was proposed explain this significant rotation (Elliott et al. 2013). Whether the other local tectonic systems, for example the Duke fault and EDF have also played important roles in accommodating the north-south crustal shortening is unknown yet. In terms of seismicity recorded in the region in the last three decades, the Duke fault is obviously more active than the EDF (Fig. 1). The 2017 double events occurred along the segments where the Duke fault is almost overlain on the EDF.

The Yukon geological survey originally proposed that the 2017 earthquake sequences were due to faulting activities along the Duke fault zone based on the seismic location and regional geological map (Cobbett et al. 2017). No surface ruptures were reported so far. As the largest events in the mainland of Canada in the past century, the 2017 earthquakes provide unique opportunities to reveal the local fault structures and mechanical properties along the Duke and Eastern Denali fault systems. In this study, we investigate these two earthquakes by organizing materials as follows: (1) To map coseismic deformation of the 2017 two earthquakes with L-band SAR interferometry (InSAR), and the ionospheric components in the InSAR results are estimated with a newly developed method proposed in this study and (2) To determine the optimal fault parameters of the two earthquakes by using InSAR and GPS coseismic measurements. Its implication on the regional stress status is provided at the end.

\section{DATA AND COSEISMIC DEFORMATION MEASUREMENTS}

\subsection{SAR interferometry}

InSAR techniques do not always work in the region of the 2017 May earthquakes due to dramatic temporal surface changes. We processed coseismic Sentinel-1 interferograms covering the earthquakes with $12 \mathrm{~d}$ intervals. However, no coherent interferogram was successfully generated due to fast snow melting during that period. The ALOS2 L-band interferometric pair of track 181, which used images acquired on 2017 April 9 and 2017 May 21, does not show enough coherence either. To reveal the coseismic surface deformation of the earthquake, we finally selected three postearthquake ALOS-2 acquisitions received in the period from June to July 2017, which are used to form three coseismic interferograms with another three pre-earthquake SLC data acquired almost
$1 \mathrm{yr}$ before. More details of the SAR data used in this study can be found in Table 1. The 30-m-resolution ASTER Global Digital Elevation Model (GDEM) was used for the InSAR processing for a valid coverage of the area over $60^{\circ} \mathrm{N}$. The data processing was performed with an InSAR processing automation environment, gInSAR developed at the Canada Center for Mapping and Earth Observation (CCMEO, Feng et al. 2016). The resultant coseismic interferograms of the three tracks fully cover the coseismic deformation of the 2017 earthquakes. To reveal potential long-term post-seismic deformation, the T181 image acquired on 20180729 (Table 1) was also collected for further deformation analysis.

\subsection{Ionospheric corrections in Track 72}

The ionospheric path delay is one of the major error sources in InSAR applications, particularly for L-band SAR interferometry (e.g. Gomba et al. 2016; Liang \& Fielding 2017). In this case, the T72 interferogram (Inf2 in Table 1) clearly shows long-wavelength signals through the whole interferogram (Fig. 2). As orbital control to ALOS2 has largely been improved in contrast to ALOS (Yamamoto et al. 2016), the phase anomaly of Inf2 is likely due to ionosphere delay.

Ionospheric path delays can lead to significant effects in different SAR deformation products. Traditional InSAR phase error from the ionospheric effects is associated with radar centre frequency. The azimuth resolution of this InSAR phase error is similar to the radar azimuth aperture length (Liang \& Fielding 2017). The ionospheric contributions in SAR phase vary with range radar frequency as range radar signal has a bandwidth. The linear component of this variation leads to the range offset. Meanwhile, the linear change of the ionospheric contribution in the SAR phase along the radar orbit can result in azimuth offset. Spatially varying offsets between master and slave cannot be sufficiently retrieved with a traditional alignment method based on a simple polynomial. This is why the ionospheric delay can sometimes result in dramatic coherence loss (Chen \& Zebker 2014). To understand the potential effects of the ionospheric contributions in the InSAR processing, we generate subpixel offset maps by using a subpixel tracking method implemented with the GAMMA software package (Wegmüller \& Werner 1997).

We firstly applied a 3-parameter polynomial to align the slave SLC of 20170703 to the SAR projection of the master 20160 704. The subpixel-offset maps in range and azimuth were computed based on the resampled slave from the last step. For the pair Inf2, range offsets (Fig. 2a) do not show significant residuals and some local scale range offsets may be due to sharp surface temporal changes (e.g. regional glacier), while large azimuth offsets of $>0.5$ pixels can be clearly observed. The azimuth residuals (Fig. 2b) are evidently not regular ramps from top to bottom, which is not correlated in space with the traditional InSAR phase of Inf2 (Fig. 2c). We filtered the subpixel offsets with a median filter by using a window size of 77 by 77 for further use. The smoothed range and azimuth offsets were utilized in resampling to re-align the slave SLC image to the master projection. The process was implemented in GAMMA. The updated resampled slave was then applied to generate a new interfergoram, which shows slight difference at a level of 0.2 radian in a narrow zone (Fig. 2d) comparing to the original interferogram (Fig. 2c). Therefore, the subpixel residuals caused by the ionospheric delay in Inf2 can be ignored. 
Table 1. Information of SAR data used for coseismic deformation mapping of the 2017 May 1 Yukon double earthquake.

\begin{tabular}{|c|c|c|c|c|c|c|c|c|}
\hline \multirow[b]{2}{*}{ Index } & \multirow[b]{2}{*}{ Track } & \multicolumn{2}{|c|}{ Time(YYYYMMDD) } & \multirow[b]{2}{*}{ Mode } & \multirow{2}{*}{$\begin{array}{c}\text { Since main } \\
\text { shock (d) }\end{array}$} & \multirow[b]{2}{*}{ Baselines $(\mathrm{m})^{\mathrm{a}}$} & \multirow[b]{2}{*}{ Ionos. } & \multirow[b]{2}{*}{ Points } \\
\hline & & Mater & Slave & & & & & \\
\hline Inf2 & 72 & 20160704 & 20170703 & StripMap & 63 & 40.9 & Yes & 5308 \\
\hline Inf3 & 73 & 20160723 & 20170722 & StripMap & 82 & -88.6 & No & 4239 \\
\hline Inf4 & 181 & 20160731 & 20180729 & ScanSAR & 454 & -14.8 & No & - \\
\hline
\end{tabular}

${ }^{\mathrm{a}}$ The perpendicular baselines.

${ }^{\mathrm{b}}$ The swath 2 and 3 of ScanSAR track 181 were processed to generate the coseismic interferogram Inf1.

Several ionospheric correction methods have been proposed previously to mitigate the effects of the ionosphere on SAR measurements (e.g. Meyer et al. 2006; Jung et al. 2013; Gomba et al. 2016). A range spectral splitting method was initially proposed by Rosen et al. (2010) and has also been extensively described toward practical applications in the recent studies (Gomba et al. 2016; Fattahi et al. 2017; Liang \& Fielding 2017). By utilizing the dispersive characteristics of ionospheric effect on microwave signal, the range spectrum splitting method can separate the ionospheric signals by using two interferograms respectively in the low and high frequency bands of the data. As the deformation signals are non-dispersive, the derived dispersive component from the low- and high-band interferograms can basically ignore the effects of deformation signals. Thus, ionospheric components can then be estimated correspondingly. Low $(l)$ or high $(h)$ bands interferograms can be formed based on the $l$ and $h$ band SAR data with corresponding centre SAR frequency. The relationship between ionospheric components and SAR frequencies can be expressed as (Gomba et al. 2016),

$\varphi_{\text {ion }}=\frac{f_{l} f_{h}}{f_{0}\left(f_{h}^{2}-f_{l}^{2}\right)}\left(\varphi_{l} f_{h}-\varphi_{h} f_{l}\right)$

where $f$ is the centre frequency for full $(0)$, high $(h)$ and low $(l)$ bands, and $\varphi$ is the phase corresponding to the different frequencies. $\varphi_{i o n}$ is the pure ionosphere component without deformation signals.

To balance the sensitivity of the method and keeping enough coherence for subband interferograms, a solution of three bands has long been recommended to use in the subbanding SAR applications (Derauw et al. 2010; Rosen et al. 2011). Like other SAR missions, the effective bandwidth of the ALOS-2 StripMap data based on the data-sampling rate is always narrower than signal bandwidth. For example, for the L-band StripMap SAR data in track 72 (Table 1), the signal range sampling bandwidth is $\sim 35 \mathrm{MHz}$, while the effective bandwidth is only $25 \mathrm{MHz}$. The fraction of the low and high frequency ends should be considered during the data splitting. This is essential to be considered in the data processing for generating low and high band SAR data with identical bandwidths. After lowand high-frequency band SLC data are generated, the spectrum of the two SLC images can be shifted to new frequency centres and ready for use in interferometry. The new frequency centres can be estimated based on the effective bandwidths of the two band SLC images. This is fundamental to correctly apply eq. (1) to get right ionospheric component.

To implement ionospheric correction following the above strategy, we develop an independent python package to split GAMMA SAR SLC data into low and high band SAR Single-Look-Complex (SLC) images at given frequency bounds. Corresponding parameters (e.g. radar frequency, chirp bandwidth) in the SLC headers of the resultant subband SLCs should be updated based on the resulting SLCs themselves. This is important to continue conducting interferometry with the GAMMA for the subband SLCs. Note that the GAMMA software applies a minor scaling of the range sampling during the SAR alignment, which could slightly influence the spectra of the resultant SLCs. Therefore, we strongly suggest carrying out the range-spectral splitting operation to the original SLC data and then perform conventional InSAR processing separately. To avoid the potential misalignment in the individual subband interferometry, the polynomials determined with the full-band SLC data are applied in the low- and high-band interferometry. If necessary, the subpixel offsets estimated with the full band SLC data can also be considered to be applied in the alignment of the subband interferometry.

Fig. 2(e) is the ionospheric component retrieved through the above operations. The subband interferomgrams are less coherent than the original interferogram. A multilooking operation with a relatively large multilooking number, for example 10 by 12 used in this case, can help reduce the noise level of the subband interferogram. This is sometimes important and acceptable as the ionospheric component is sensitive to the unwrapping errors and long-wavelength signals. Low-coherent interferograms can always increase the chance to have significant unwrapping errors. The final corrected interferogram of Inf2 (Fig. 2f) shows a single deformation centre with maximum deformation of $\sim 0.12 \mathrm{~m}$ in the light-of-sight (LOS) direction without long-wavelength signals, implying that the package developed in this study works well for ionosphere correction.

\subsection{Deformation anomalies in Track 73}

We generated track 73 interfergoram (Inf3) with similar processing procedures as described in the Section 2.2 for Inf2. A similar deformation pattern with Inf2 is directly observed in the traditional coseismic interferogram of Track 73 (Inf3, Table 1, Fig. 3). However, a zone perpendicular to the satellite flight direction at the bottom of the image shows dramatic range offset residuals of $0.3-$ 0.8 pixel (Fig. 3a) while the azimuth subpixel offset map gives a more complicated offset distribution (Fig. 3b).

As no evident deformation signals can be found in the corresponding position in the traditional interferogram (Fig. 3c), we do not attribute the offsets to the ionosphere delay. We suspect that the irregular offsets through the image may be due to a potential bug during the ALOS2 SLC data generation. As shown in Fig. 3(d), the updated interferogram after the subpixel offset compensation implemented in the alignment can have $\sim 0.35$ radian difference relative to the original interferogram (Fig. 3c). Note that the coherence of the updated interferogram can at least be significantly improved. For Inf3, the mean coherence increase from 0.56 to 0.61 (Fig. S1). Therefore, subpixel offsets can be suggested to be regularly involved 


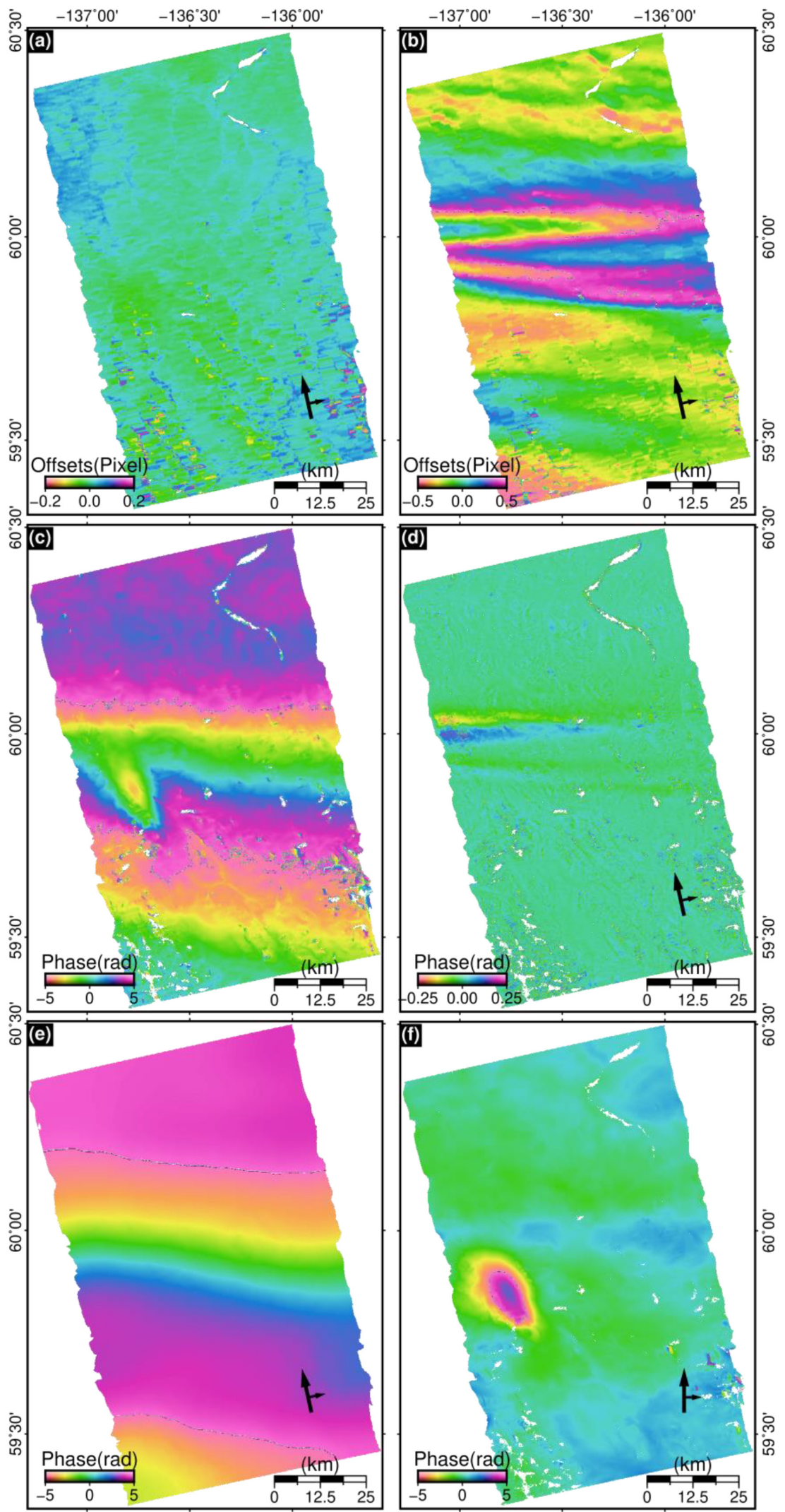

Figure 2. Effects of ionosphere delays in T72 interferogram of $20160704-20170703$ and correction. (a) Range subpixel offsets of the T72 interferogram. (b) Azimuth subpixel offsets. (c) Traditional InSAR interferogram. (d) The phase difference between (c) and an updated interferogram that is created after the subpixel offsets of (a) and (b) are involved in slave SLC resampling. (e) Ionospheric component derived with the range spectral split method. (f) The improved InSAR phase after removing (e). Note that all products are rewrapped within their own specified ranges. The colour version of this figure is available only in the electronic edition. 


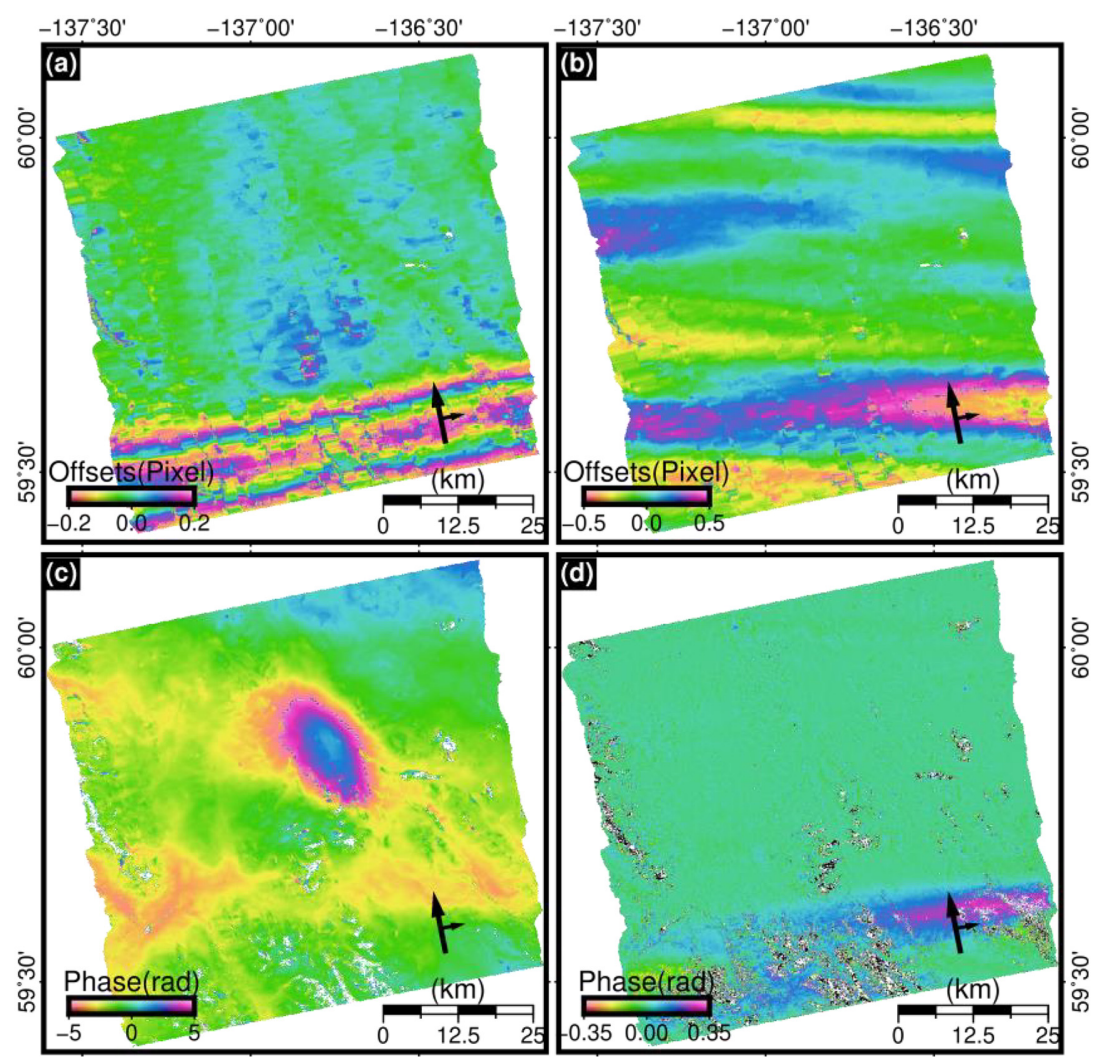

Figure 3. Anomaly analysis of Track 73 interferogram of 20160 723-20 170 722. (a) Range subpixel offsets. (b) Azimuth subpixel offsets. (c) Traditional interferogram fringes. (d) As Fig. 2, the difference between (c) and an updated interferogram that is generated with subpixel offsets involved in the resampling. The colour version of this figure is available only in the electronic edition.

in a conventional L-band InSAR processing if processing time is not an issue. For the Permanent Scatterers (PS) identification purpose, the phase errors due either to ionosphere or SLC generation issues may be compensated with accurate subpixel estimation, particularly with L-band SAR data.

Troposphere delay may also cause phase errors in InSAR measurements (e.g. Zebker et al. 1997). To account for the potential tropospheric delays in this study, we generated atmospheric correction maps using the Generic Atmospheric Correction Online Service for InSAR (GACOS) system developed at Newcastle University, United Kindom (Yu et al. 2017, 2018). After the tropospheric correction for Inf2 was applied, the standard deviation of the Inf2 LOS changes slightly decreases from 8.6 to $8.0 \mathrm{~mm}$, implying that the correction of the troposphere delay in Inf2 is insignificant. The similar situation can also be found for Inf3, of which the standard deviation drops to 6.0 from $7.3 \mathrm{~mm}$.

Small LOS change residuals at a level of $5 \mathrm{~mm}$ can be observed after the correction in the far field of the three interferograms (Figs 2 and 3), which is most likely due to the effects of permafrost. In northern Canada, permafrost is the major mechanism to drive surface changes (Short et al. 2011; Samsonov et al. 2015). In comparison to the maximum LOS surface deformation of $\sim 0.10 \mathrm{~m}$ in the earthquake area, the residuals in the far field would not bias the results of earthquake parameters inversion.

Three deformation components at GPS station TRTH were selected by He et al. (2018) in their modelling. TRTH is located near the epicentre of eq. (1), which moved $5.53 \pm 2.29 \mathrm{~mm}$ eastward, $-14.12 \pm 1.87 \mathrm{~mm}$ southward and $55.16 \pm 4.9 \mathrm{~mm}$ upward. The three measurements are used in the inversion in Section 3.

\section{GEOPHYSICAL MODELLING AND RESULTS}

In order to reduce computational burden in the inversion in handling the InSAR measurements, we downsampled the three coseismic interferograms (Table 1) into discrete points using a Resolution-Based (RB) quadtree method (Table 1, Lohman \& Simons 2005). A simple fault model is required in the RB downsampling algorithm; in this case we marked a single fault trace based on the coseismic deformation fringe of Infl as it has clear two deformation lobes. Note that this fault location was only used for the downsampling purpose. Since the coherence of each interferogram is generally good, we used an identical weight for each dataset in the inversion. An elastic half-space dislocation model was employed in the inversion to calculate theoretical surface response from slip (Okada 1985), in which a Poisson's ratio of 0.25 is applied.

The location ( $x, y$ and depth), geometric parameters (e.g. strike, dip, rake, length and width) of a fault are nonlinearly proportional to the surface deformation. As no surface rupture was reported from the field survey for both events, a non-linear global search was conducted firstly to estimate the above mentioned parameters with a semi-automatic geodetic inversion package, PSOKINV (Feng et al. $2010,2013,2017)$. The package is equipped with a hybrid nonlinear global search algorithm (Feng \& Li 2010), MPSO that is an optimization method for implementing nonlinear global searching by simulating praying behaviours of flock of birds. MPSO is an updated version of Particle Swarm Optimization (PSO, Eberhart \& Kennedy 1995), in which a certain number of particles are initially placed in the given parameter space randomly and they return the 
Table 2. Source parameters of the 2017 Yukon earthquakes.

\begin{tabular}{|c|c|c|c|c|c|c|c|c|c|c|c|}
\hline \multirow[b]{2}{*}{$\operatorname{Ind}^{\mathrm{b}}$} & \multirow[b]{2}{*}{ Source } & \multicolumn{2}{|c|}{ Location $^{\mathrm{a}}$} & \multicolumn{3}{|c|}{ Focal Mechanisms } & \multirow[b]{2}{*}{ Depth (km) } & \multicolumn{2}{|c|}{ Dimension } & \multirow[b]{2}{*}{$\mathrm{S}(\mathrm{m})$} & \multirow[b]{2}{*}{$M_{\mathrm{w}}$} \\
\hline & & Lon & Lat & Strike & Dip & Rake & & Length & Width & & \\
\hline \multirow[t]{3}{*}{ E1 } & USGS & -136.711 & 59.821 & 165 & 66 & 130 & 15.5 & - & - & - & 6.3 \\
\hline & InSAR & $-136.693(\#)$ & $59.830(\#)$ & $153.1 \pm 1.7$ & $64.0 \pm 1.7$ & $97.7 \pm 2.7$ & $9.3 \pm 0.3$ & $24.0 \pm 2.0$ & $3.4 \pm 1.6$ & $0.9 \pm 0.4$ & $6.2^{\mathrm{a}}$ \\
\hline & InSAR + GPS & $-136.706(\#)$ & $59.848(\#)$ & $150.7 \pm 5.1$ & $63.0 \pm 2.9$ & $98.2 \pm 3.5$ & $9.3 \pm 0.6$ & $19.2 \pm 2.0$ & $3.9 \pm 2.4$ & $1.0 \pm 0.4$ & $6.2^{\mathrm{a}}$ \\
\hline \multirow{3}{*}{ E2 } & He et al. (2018) & -136.704 & 59.830 & 187 & 83 & 168 & 11.0 & - & - & - & 6.2 \\
\hline & InSAR & $-136.686(\#)$ & 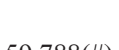 & $182.9 \pm 2.8$ & $69.0 \pm 7.3$ & $170.2 \pm 1.7$ & $7.7 \pm 0.6$ & $10.7 \pm 2.0$ & $6.4 \pm 2.4$ & $1.0 \pm 0.5$ & $6.2^{\mathrm{a}}$ \\
\hline & InSAR + GPS & $-136.687(\#)$ & $\begin{array}{l}59.788(\#) \\
59.767(\#)\end{array}$ & $184.6 \pm 4.6$ & $75.5 \pm 12.1$ & $171.4 \pm 2.5$ & $8.4 \pm 0.7$ & $7.5 \pm 5.5$ & $7.8 \pm 2.9$ & $2.5 \pm 2.2$ & $6.2^{\mathrm{a}}$ \\
\hline
\end{tabular}

*, the epicentre given by USGS is the initial motion of the events.

\# The locations presented in Table 2 from the InSAR modelling are the centre of the rectangle fault patches.

${ }^{a}$ The geodetic moment magnitudes of the two events were fixed in this study. A shear module of $30 \mathrm{GP}$ is applied in the conversion from the fault model to the moment magnitude.

${ }^{\mathrm{b}} \mathrm{E} 2$ for the early event at 12 O'clock (UTC) on 2017 May 1 and E1 for the $2 \mathrm{hr}$ later event.
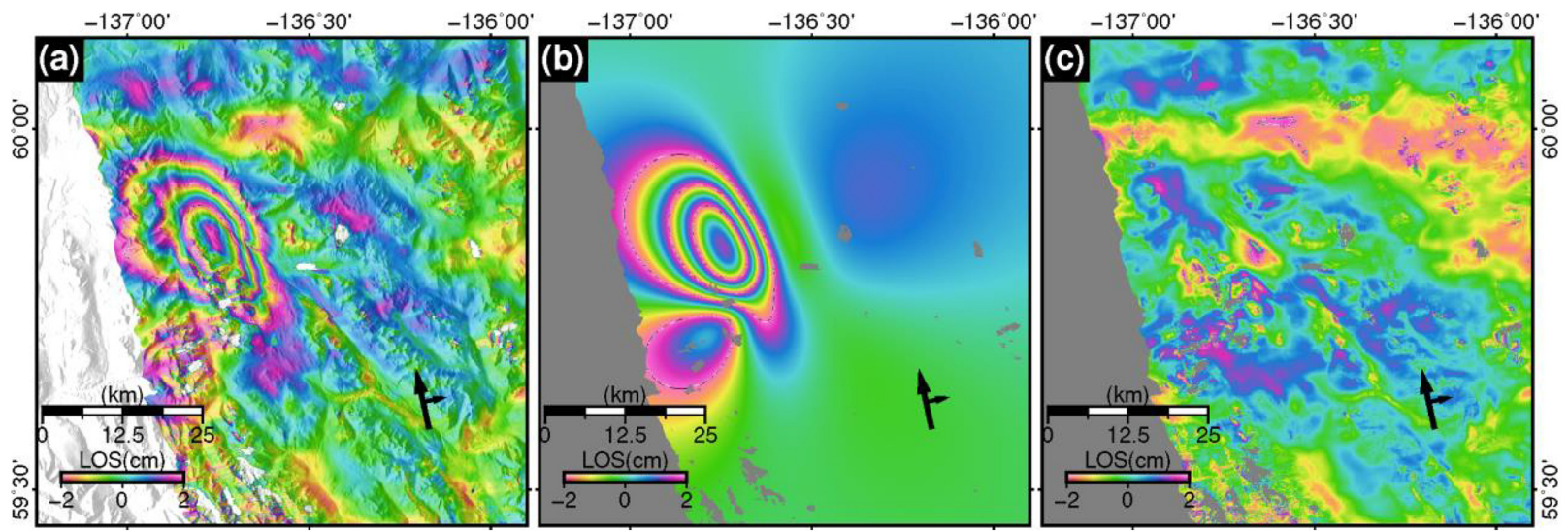

Figure 4. Data fitting of Track $72\left(\begin{array}{lllll}20 & 160 & 704-20 & 170 & 703\end{array}\right)$ with the best-fitting fault model determined with the GPS and InSAR observations. The long thick arrows show the flight direction of the satellite and the short ones give the looking direction. The three interferograms are rewrapped within a range of -2 to $2 \mathrm{~cm}$. The colour version of this figure is available only in the electronic edition.
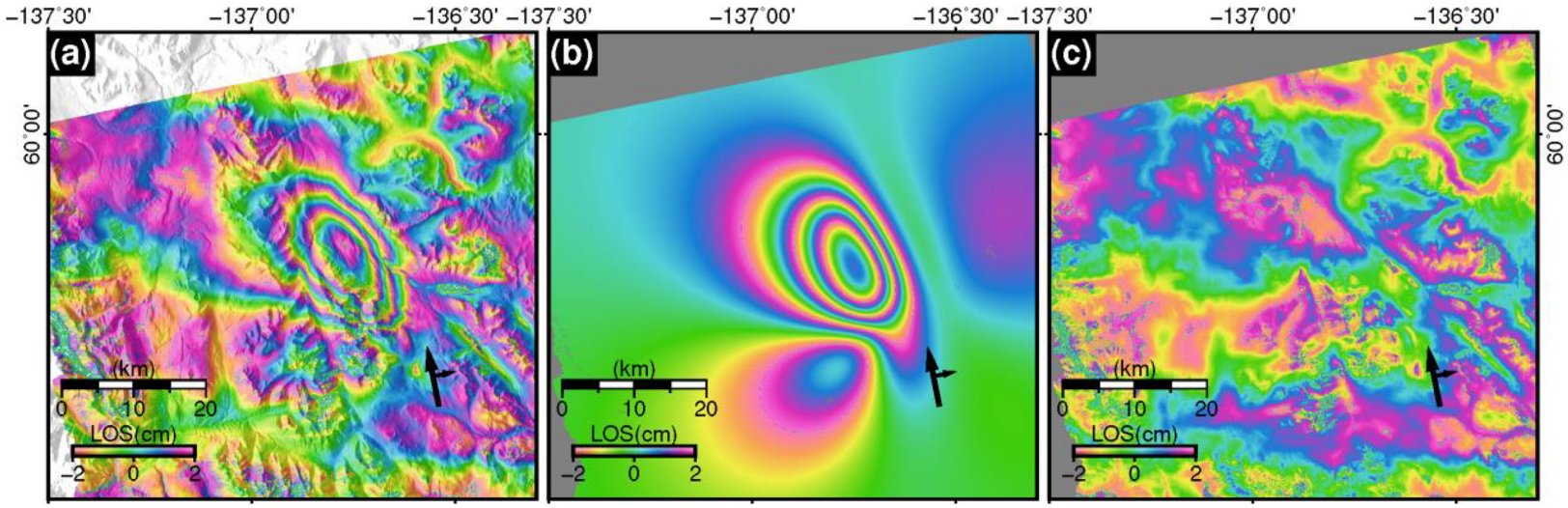

Figure 5. As Fig. 4, but for the interferogram of Track 73 (20 $\left.160 \begin{array}{llll}20 & 723-20 & 170 & 722\end{array}\right)$. The three interferograms in Fig. 4 are also rewrapped within a range of -2 to $2 \mathrm{~cm}$. The colour version of this figure is available only in the electronic edition.

information of data fitting at those positions to the control centre. In the following steps, all particles will 'fly' to next positions based on both the global optimal position with a global minimum in history and a local minimum optimal position estimated from its individual searching history. MPSO also incorporates a downhill simplex method (Nelder \& Mead 1965) to speed up the local searching processing to reduce total computational cost. MPSO has been successfully used in over 20 earthquakes, for example 2011 


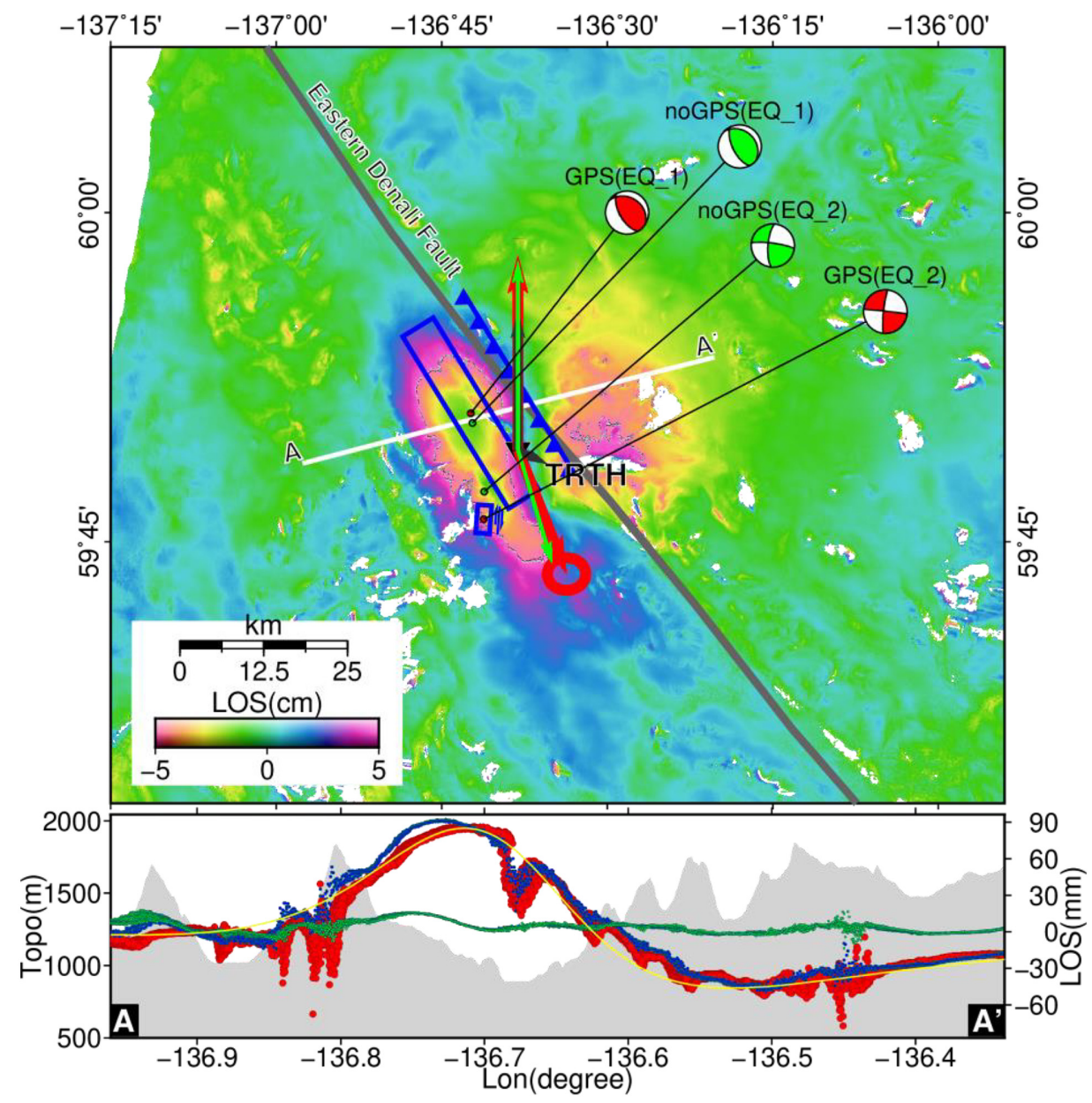

Figure 6. Spatial location of the best-fitting uniform slip faults inferred from the joint inversion of the InSAR and GPS data, and the GPS coseismic changes with the coseismic interferogram of T181 (20 160 731-20 170 730), where the GPS coseismic data were adopted from He et al. (2018). The beach ball symbols are based on the fault solutions of the InSAR only data and a combination of the InSAR and GPS data, respectively. Red vectors are the coseismic displacements of GPS site TRTH, while black vectors are based on the InSAR only model, green ones are from the join inversion. In the displacements analysis along the profile AA', red dots are from the T72 interferogramT181 coseismic interferogram, blue dots are from the coseismic interferogram of $20160731-$ 20180729 , and green dots are from the only post-seismic interferogram of 20170 730-20 180729 in the track T181. Yellow line is predicted with the best-fitting fault models inferred from the joint inversion. The colour version of this figure is available only in the electronic edition.

Yushu earthquake (Li et al. 2011), 2016 Pishan earthquake (Li et al. 2017) and $2017 M_{\mathrm{w}} 7.3$ Iran border earthquake (Feng et al. 2018).

All the three coseismic InSAR interferograms cover both events. To avoid a strong trade-off of the contributions of the two events to the InSAR LOS range changes, we designed an objective function to utilize the seismic moment magnitudes and to additionally constrain individual faults partly to meet seismic solutions.

$$
\begin{aligned}
\varphi_{j}= & \sum\left(W\left(\sum_{i=0}^{n} f\left(m_{j}^{i}\right)-d\right)\right)^{2} \\
& \times \exp \left(\sum_{i=0}^{n}\left(\left|M W\left(m_{j}^{i}\right)-n_{i}\right| * 10\right)\right),
\end{aligned}
$$

where $W$ is the weight matrix with setting the diagonal elements to 1 in this case, $f\left(m_{i}^{j}\right)$ is a forward surface deformation function based on a Okada dislocation model (Okada 1985) and $m_{i}^{j}$ is the $i$ th fault model in $j$ th test, $d$ is the InSAR LOS displacements, $M W\left(m_{i}^{j}\right)$ is the moment magnitude function. $n_{i}$ is a given reference moment magnitude of $i$ th fault. In this case, we used He et al. (2018)'s results to fix $n_{i}$ to $M_{\mathrm{w}} 6.2$.
The coseismic interferograms Inf2 and Inf3 have similar SAR viewing geometries (Table 1). After a number of numerical tests, significant topography-correlated signals can be observed in the residual of Inf3. Either third-part APS model or linear topographyrelated correction cannot fully account for those residuals (Fig. 5), which may be mainly due to some fast temporal changes (e.g. snow, ice or other permafrost related surface changes). Therefore, we did not include Inf3 in the inversion.

Table 2 shows the best-fitting fault parameters determined under the constraints of the InSAR observations only and the combination of the InSAR and GPS data, respectively. The GPS data mainly affect the fault scales. The focal mechanisms of the two events are consistent with the seismic locations from He2018 on the two west-dipping fault planes, of which eq. (1) is related mainly to upward motion on a steep reverse fault and eq. (2) is controlled with left-lateral slip and a small percentage of thrusting component. Evidently, the InSAR-only and joint inversion results both consistently suggest shallower source depths than the USGS early solutions; and the optimal source depths determined in this study are similar to He2018. The coseismic deformation lobes can be fully reproduced 


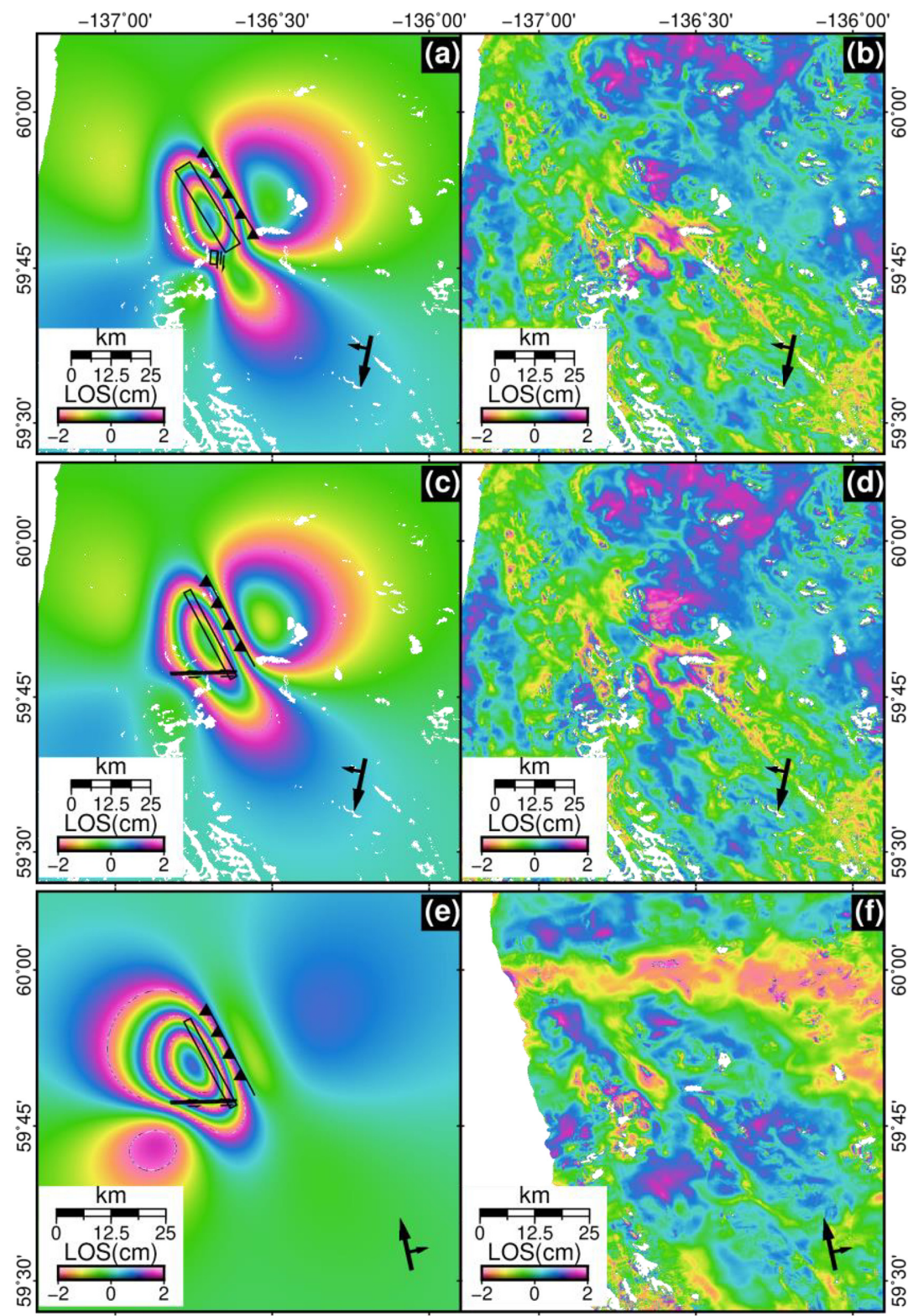

Figure 7. (a) The prediction of the interferogram of $20160731-20170730$ with the best-fitting fault model referred from the joint inversion. (b) The residual after removing (a) from the original interferogram as shown in Fig. 6. (c) The prediction of (a) from the conjugate fault model of eq. (2). (d) Residuals after subtracting (c) from (a). (e-f) as (c-d), but for the interferogram of $20 \quad 160 \quad 704-20170703$. All interferograms are rewrapped within a range of -2 to $2 \mathrm{~cm}$. The colour version of this figure is available only in the electronic edition.

with the best-fitting fault models (Figs 4 and 5). The standard deviation of residuals of the downsampled points are 8 and $9 \mathrm{~mm}$ for the pure InSAR and the joint inversion of the GPS and InSAR models, respectively. However, the InSAR-only model cannot account for GPS surface displacements well (Fig. 6), particularly the south-north (SN) component. This implies an inherent InSAR limitation in measuring surface displacements again, which is that the resolution of InSAR measurements in the SN direction is weak. With several numerical tests, a relative weight of 20 to the InSAR data was finally selected to return reasonable results, in which the InSAR and GPS data were both be able to be fitted nicely.

Using an InSAR-error estimation based Monte Carlo analysis (Funning et al. 2005), we estimated the uncertainties of the fault parameters (Figs S2 and S3). Strong trade-offs of the fault parameters show a general non-uniqueness of geophysical inversion. The fault width of eq. (2) is sensitive to the slip (Fig. S2). By involving the GPS data, the best-fitting model preferentially converged to a solution with a narrower fault of $2.4 \mathrm{~km}$ but a slip of $>2 \mathrm{~m}$. It is difficult to estimate the absolute uncertainties of the solution as the InSAR deformation maps includes the two earthquake and some small-scale temporal changes as well. As pointed by He2018, the GPS data may be contaminated by the permafrost changes too. At least, the focal mechanisms from the InSAR-only and joint inversions are consistent, which also further validate the solution of He2018. The surface projection of eq. (1) is almost identical with the Eastern Denali Fault (EDF, Fig. 6). 


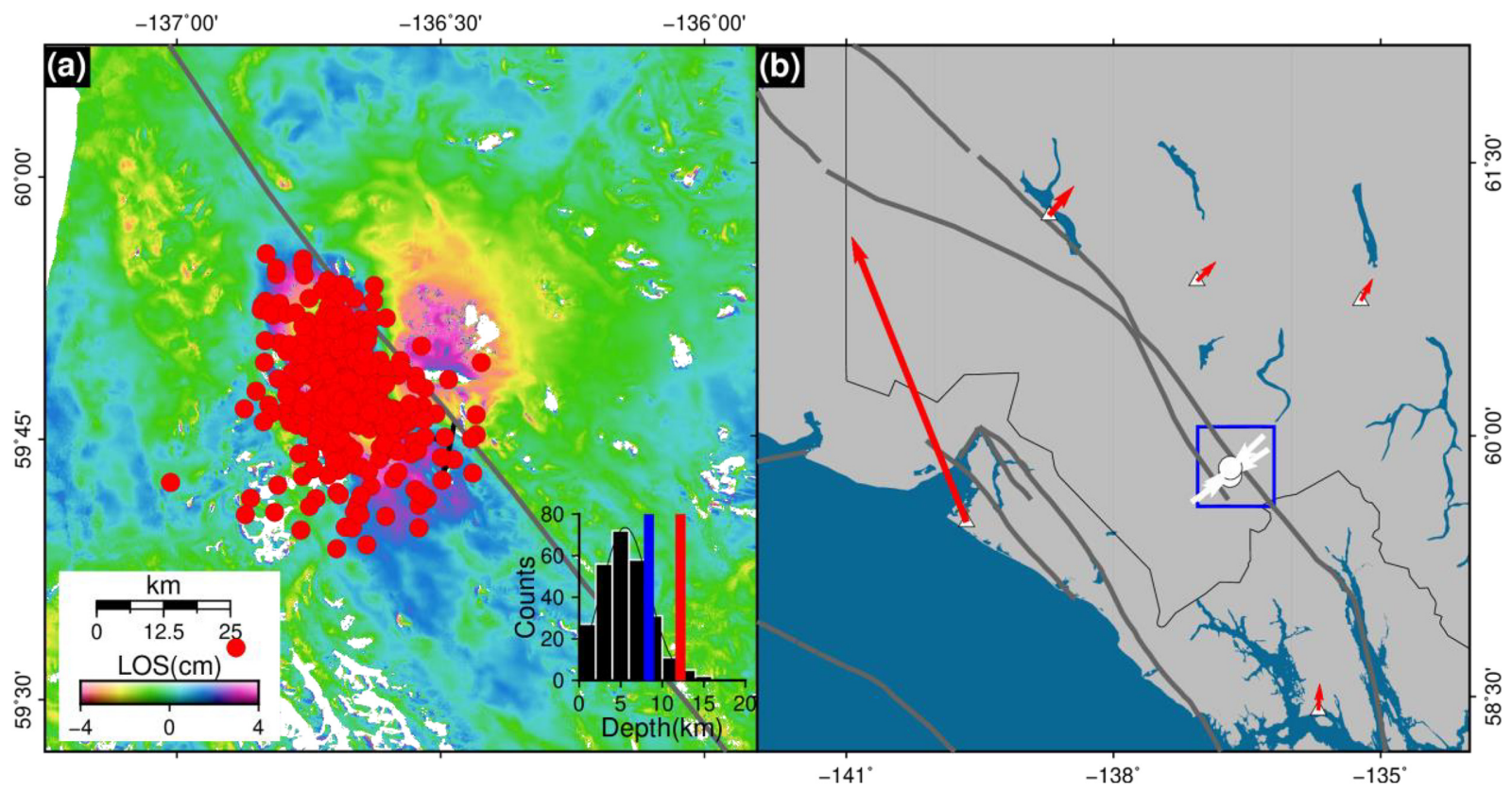

Figure 8. (a) Aftershocks distribution in space and depth, respectively. The aftershocks are for the period from 2017 May 1 to 2017 November 8 , recorded by the USGS data centre. (b) Interseismic GPS velocities (red) and maximum horizontal stress (white arrows) inferred from the earthquake mechanisms. The colour version of this figure is available only in the electronic edition.

\section{DISCUSSION}

The best-fitting fault models inferred from the joint inversion of the InSAR and GPS data indicate that the two events did not rupture to the surface. Potential post-seismic observations can be very helpful for one to estimate post-seismic seismic hazard and understand the fault physical properties (Rosen et al. 1998; Barbot et al. 2009; Chen et al. 2013). Unfortunately, we missed the best observation time window for the earthquakes due to the fast snow melting in the region.

In this study, the selected post-seismic acquisitions were all made in July of 2017, almost 2 months after the main shocks. These interferograms used in the inversion cover the coseismic and first 2 months' post-seismic deformation. We made an analysis along the profile AA' (Fig. 6), which is almost across the largest LOS displacement zone in Track 181. The observations within a buffer zone of a $500 \mathrm{~m}$ along AA' are plotted in Fig. 6. The maximum LOS displacement is $\sim 90 \mathrm{~mm}$, with the minimum displacement of $\sim-45 \mathrm{~mm}$. Inf2 (red dots) and Inf4 (blue does) are generally in good agreement. Particularly, around E136.7 across a valley, Inf2 and Inf4 both present a sharp phase jump of $50 \mathrm{~mm}$, which is likely resulting from a shallow slip event. In the coseismic map of Inf1 (Fig. 6), a linear feature can also be identified around the epicentre of eq. (1). It is hard to estimate with the limited data on whether the phase jump was caused by an aftershock or aseismic slip as lacking of rapid post-seismic observations. Based on the information of the deformation profile, we can at least know that the shallow zone of the EDF has been partly activated in either seismic or aseismic ways.

As mentioned in He2018, a potential conjugate fault of eq. (2) can also produce similar coseismic deformation. The west-dipping fault can fit the GPS slightly better than its conjugate fault. It is common to have similar surface deformation patterns from slips on two conjugate fault planes (Feng 2015), particularly for those with deep sources at $\sim 10 \mathrm{~km}$ or greater. The unique deformation patterns due to the fault spatial scale on the surface cannot be directly revealed in the InSAR measurements due to the common data errors, in which the deformation signals in the far field have been smaller than the effects of APS. The recent several studies also reveal that their InSAR deformation products cannot fully identify the responsible fault from the conjugate fault models (e.g. Li et al. 2017). To examine the possibility of the conjugate fault of eq. (2) for the earthquakes, we restarted the inversion with a constraint of strike of eq. (2) at a narrow range of 260-310.

The best-fitting model with a fixed north-dipping fault has focal mechanisms of strike 270.1 , dip 87.9 and rake 9 on a nearly vertical fault plane, which can fit Infl generally well (Fig. 7) with a RMS of $9.9 \mathrm{~mm}$ for the all downsampled points. The residual is slightly worse than the RSM of $9 \mathrm{~mm}$ from the west-dipping fault model. The prediction of Inf2 with the north dipping fault model is almost identical with that from the west-dipping model. It hardly tells which model could be reasonable for the earthquake only based on the InSAR data fits. Based on the local topography, no signs for any north dipping fault can be figured out. In addition, a north-dipping fault would have cut the local mountain range and valleys. Logically, it is not likely true and we then agree with He2018's conclusion that the both west-dipping faults should be associated with the May 1 earthquakes of 2017.

Almost 350 aftershocks occurred in the period from 2017 May 1 to 2017 November 8 recorded by the USGS data centre. We ruled out those with depth of $10 \mathrm{~km}$ that means unsolved for depth due to large uncertainty. The remaining data show that the most aftershocks were concentrated at depths from 0 to $10 \mathrm{~km}$ (Fig. 8a). As a potential shallow event may have also been identified in the coseismic interferogram of Inf1, we would conclude that the shallow crust was re-activated after the May earthquake sequences and no clear seismic gap can be observed, implying that the chance having another high seismic risk in the region could be low.

Based on the optimal fault mechanisms derived from the geodetic observations, $P$-axes are 229.5 and 229.2 for eqs (1) and (2), 
respectively (Fig. 8b). These two angles are similar to those estimated by $\mathrm{He} 2018$, but the results in this study are more consistent between the two events. The $P$-axes are consistent with the regional NE-SW compressional stress status as well (Heidbach et al. 2010). The interseismic GPS velocities (Fig. 8b) then indeed shows the localized the stress status, which is already moving northeast, implying dramatic rotations of tectonic mechanics from the coastal area to the inland of the Yukon Territory.

\section{CONCLUSIONS}

The 2017 May $1 M_{\mathrm{w}} 6.2$ earthquake doublet in Yukon, Canada was investigated using geodetic observations. We developed a pythonbased ionospheric correction package within the framework of the GAMMA software to correct L-band interferograms for ionospheric effects. The corrected interferograms clearly revealed the distinguishable deformation patterns and were used together with the GPS observations to estimate the source parameters of the two earthquakes. The best-fitting fault models suggest that a thrust faulting on a steep fault of dip 61 and another left-lateral strike-slip faulting with thrust component should take major responsibility of the two events, respectively. The geodetic results are in good agreement with seismic solutions obtained by He et al. (2018). Based on the fault location and regional fault map, the 2017 two earthquakes should be related to the reactivation of part of the Eastern Denali Fault (EDF).

Due to fast seasonal snow melting in the Yukon Territory, no coherent InSAR measurements with C-band Sentinel-1 TOPS data which were acquired $12 \mathrm{~d}$ apart were obtained for deformation mapping of the two earthquakes. Even L-band SAR interferometry with a time interval shorter than 3 months failed too. Finally, interferometric pairs of the L-band SAR data acquired in the similar months of consecutive years can maintain good interferometric coherence. This implies that it might be ideal for future SAR missions, for example the Canadian RADARSAT Constellation Mission (RCM), to collect data with short temporal baselines, or at least to receive data annually from the same month for potential applications with interferometry in that region.

\section{ACKNOWLEDGEMENTS}

We sincerely thank the Editor and two reviewers' thorough reviews which significantly improved the manuscript. We thank JAXA for providing ALOS2 ScanSAR and StripMap SAR data through a RA6 PI project (3159). We also thank Mrs Rosie Cobbett from the Yukon geological survey for providing local geological information. Dr Xiaohui He is thanked for providing the GPS data and sharing their newly published results on the two events. We also thank the funding from Guangdong Province Introduced Innovative R\&D Team of Geological Processes and Natural Disasters around the South China Sea (2016ZT06N331). All figures are prepared with the Genetic Mapping Tool (GMT) (Wessel \& Smith 1998; Wessel et al. 2013). We thank Dr Urs Wegmuller and Dr Charles L. Werner for the insightful comments on the use of the GAMMA software package. The work related with GACOS was partly supported by the UK NERC through the Centre for the Observation and Modelling of Earthquakes, Volcanoes and Tectonics (COMET, ref.: come30001) and the LICS project (ref. NE/K010794/1).

\section{REFERENCES}

Barbot, S., Fialko, Y. \& Bock, Y., 2009. Postseismic deformation due to the Mw6.0 2004 Parkfield earthquake: stress-driven creep on a fault with spatially variable rate-and-state friction parameters, J. geophys. Res., 114, doi:10.1029/2008JB005748.

Chen, A.C. \& Zebker, H.A., 2014. Reducing Ionospheric effects in InSAR data using accurate Coregistration, IEEE Trans. Geosci. Remote Sens., 52, 60-70.

Chen, K.H., Bürgmann, R. \& Nadeau, R.M., 2013. Do earthquakes talk to each other? Triggering and interaction of repeating sequences at Parkfield, J. geophys. Res.: Solid Earth, 118, 165-182.

Christeson, G.L., Gulick, S.P.S., van Avendonk, H.J.A., Worthington, L.L., Reece, R.S. \& Pavlis, T.L., 2010. The Yakutat terrane: dramatic change in crustal thickness across the transition fault, Alaska, Geology, 38, 895898.

Cobbett, R., Israel, S., Mortensen, J., Joyce, N. \& Crowley, J., 2017. Structure and kinematic evolution of the duke river fault, southwestern yukon 1 , Can. J. Earth Sci., 344, 322-344.

Derauw, D., Orban, A. \& Barbier, C., 2010. Wide band SAR sub-band splitting and inter-band coherence measurements, Remote Sens. Lett., 1, 133-140.

Doser, D.I., Pelton, J.R. \& Veilleux, A.M., 1997. Earthquakes in the Pamplona zone, Yakutat block, south central Alaska, J. geophys. Res. Earth, 102, 24499-24511.

Dziewonski, A.M., Chou, T.-A. \& Woodhouse, J.H., 1981. Determination of earthquake source parameters from waveform data for studies of global and regional seismicity, J. geophys. Res., 86, 2825-2852.

Eberhart, R. \& Kennedy, J., 1995. A new optimizer using particle swarm theory, in MHS'95. Proceedings of the Sixth International Symposium on Micro Machine and Human Science, pp. 39-43, doi:10.1109/MHS.1995.494215.

Elliott, J., Freymueller, J.T. \& Larsen, C.F., 2013. Active tectonics of the St. Elias orogen, Alaska, observed with GPS measurements, J. geophys. Res.: Solid Earth, 118, 5625-5642.

Fattahi, H., Simons, M. \& Agram, P., 2017. InSAR Time-Series estimation of the Ionospheric phase delay: an extension of the split Range-Spectrum technique, IEEE Trans. Geosci. Remote Sens., 55, 5984-5996.

Feng, W., 2015. Modelling co- and post-seismic displacements revealed by InSAR and implications for fault behaviour, Sch. Geogr. Earth Sci. University of Glasgow, Glasgow.

Feng, W. \& Li, Z., 2010. A novel hybrid PSO/simplex algorithm for determining earthquake source paramers using InSAR data, Prog. Geophys., (In Chinese), 25, 1189-1196.

Feng, W., Li, Z., Elliott, J.R., Fukushima, Y., Hoey, T., Singleton, A., Cook, R. \& Xu, Z., 2013. The 2011 MW 6.8 Burma earthquake: fault constraints provided by multiple SAR techniques, Geophys. J. Int., 195, 650-660.

Feng, W., Omari, K. \& Samsonov, S.V.V., 2016. An automated insar processing system: potentials and challenges, in Proceedings of the 2016 IEEE International Geoscience and Remote Sensing Symposium (IGARSS), doi:10.1109/IGARSS.2016.7729830.

Feng, W., Samsonov, S., Almeida, R., Yassaghi, A., Li, J., Qiu, Q., Li, P. \& Zheng, W., 2018. Geodetic constraints of the 2017 Mw7.3 Sarpol Zahab, Iran Earthquake, and its implications on the structure and mechanics of the northwest zagros Thrust-Fold belt, Geophys. Res. Lett., doi:10.1029/2018GL078577.

Feng, W., Tian, Y., Zhang, Y., Samsonov, S., Almeida, R. \& Liu, P., 2017. A slip gap of the $2016 \mathrm{M}$ w 6.6 Muji, Xinjiang, China, Earthquake inferred from Sentinel-1 TOPS interferometry, Seismol. Res. Lett., 88, 1054-1064.

Feng, W., Xu, L., Li, Z., Li, C. \& Xu, Z., 2010. Fault parameters of the October 2008 Damxung Mw 6.3 earthquake from InSAR inversion and its tectonic implication, Chinese J. Geophys., Chinese Ed., 53, 1134-1142.

Fletcher, H.J. \& Freymueller, J.T., 1999. New GPS constraints on the motion of the Yakutat block, Geophys. Res. Lett., 26, 3029-3032.

Fuis, G.S. et al., 2008. Trans-Alaska crustal transect and continental evolution involving subduction underplating and synchronous foreland thrusting, Geology, 36, 267-270. 
Funning, G.J., Parsons, B. \& Wrigth, T.J., 2005. Surface displacements and source paramenters of the 2003 Bam (Iran) earthquake from Envisat advanced synthetic aperture radar imagery, J. geophys. Res., 110, doi:10.1029/2004JB003338.

Gomba, G., Parizzi, A., De Zan, F., Eineder, M. \& Bamler, R., 2016. Toward operational compensation of Ionospheric effects in SAR Interferograms: the Split-Spectrum method, IEEE Trans. Geosci. Remote Sens., 54, 14461461.

Haeussler, P.J., 2009. Surface rupture map of the 2002 M7.9 denali fault earthquake, Alaska, Digital Data. US Geol. Surv. Data Sci., 422.

Haeussler, P.J. et al., 2004. Surface rupture and slip distribution of the Denali and totschunda faults in the 3 November 2002 M 7.9 earthquake, Alaska, Bull. seism. Soc. Am., 94, S23-S52.

He, X., Ni, S., Zhang, P. \& Freymueller, J., 2018. The 1 May 2017 British Columbia-Alaska Earthquake doublet and implication for complexity Near Southern end of denali fault system, Geophys. Res. Lett., 45, 59375947.

Heidbach, O., Tingay, M., Barth, A., Reinecker, J., Kurfeß, D. \& Müller, B., 2010. Global crustal stress pattern based on the World Stress Map database release 2008, Tectonophysics, 482, 3-15.

Jung, H.S., Lee, D.T., Lu, Z. \& Won, J.S., 2013. Ionospheric correction of SAR Interferograms by multiple-aperture interferometry, Geosci. Remote Sens., IEEE Trans., 51, 3191-3199.

Koons, P.O., Hooks, B.P., Pavlis, T., Upton, P. \& Barker, A.D., 2010. Threedimensional mechanics of Yakutat convergence in the southern Alaskan plate corner, Tectonics, 29, 1-17.

Leonard, L.J., Hyndman, R.D., Mazzotti, S., Nykolaishen, L., Schmidt, M. \& Hippchen, S., 2007. Current deformation in the northern Canadian Cordillera inferred from GPS measurements, J. geophys. Res.: Solid Earth, 112, 1-15.

Li, Y., Luo, Y., Zhang, J. \& Jiang, W., 2017. The 2015 Mw 6.4 Pishan earthquake, China: geodetic modelling inferred from Sentinel-1A TOPS interferometry, Surv. Rev., 1-9, doi:10.1080/00396265.2017.1335381.

Li, Z., Elliott, J.R., Feng, W., Jackson, J.A., Parsons, B.E. \& Walters, R.J., 2011. The 2010 MW6.8 Yushu (Qinghai, China) earthquake: Constraints provided by InSAR and body wave seismology, J. geophys. Res.: Solid Earth, 116, doi:10.1029/2011JB008358.

Liang, C. \& Fielding, E.J., 2017. Measuring azimuth deformation with LBand ALOS-2 ScanSAR interferometry, IEEE Trans. Geosci. Remote Sens., 55, 2725-2738.

Lisowski, M., Savage, J.C. \& Burford, R.O., 1987. Strain accumulation across the fairweather and Totschunda Faults, Alaska, J. geophys. Res., 92, 11552

Lohman, R.B. \& Simons, M., 2005. Some thoughts on the use of InSAR data to constrain models of surface deformation: noise structure and data downsampling, Geochem., Geophys. Geosyst., 6, Q01007, doi: $10.1029 / 2004 \mathrm{gc} 000841$.

Matmon, A., Schwartz, D.P., Haeussler, P.J., Finkel, R., Lienkaemper, J.J., Stenner, H.D. \& Dawson, T.E., 2006. Denali fault slip rates and Holocene-late Pleistocene kinematics of central Alaska, Geology, 34, 645-648.

Mazzotti, S. \& Hyndman, R.D., 2002. Yakutat collision and strain transfer across the northern Canadian Cordillera, Geology, 30, 495-498.

Meyer, F., Bamler, R., Jakowski, N. \& Fritz, T., 2006. The potential of low-frequency SAR systems for mapping Ionospheric TEC distributions, Geosci. Remote Sens. Lett. IEEE, 3, 560-564.

Nelder, J. \& Mead, R., 1965. A simplex method for function minimization, Comput. J., 7, 308-313.

Okada, Y., 1985. Surface deformation due to shear and tensile faults in a half-space, Bull. seism. Soc. Am., 85, 1135-1154.

Rosen, P., Lavalle, M., Pi, X., Buckley, S., Szeliga, W., Zebker, H. \& Gurrola, E., 2011. Techniques and tools for estimating ionospheric effects in interferometric and polarimetric SAR data, in Geoscience and Remote
Sensing Symposium (IGARSS), 2011 IEEE International, pp. 1501-1504, doi:10.1109/igarss.2011.6049352.

Rosen, P., Werner, C., Fielding, E., Hensley, S., Buckley, S. \& Vincent, P., 1998. Aseismic creep along the San Andreas Fault northwest of Parkfield, CA measured by radar interferometry, Geophys. Res. Lett., 25, 825-828.

Rosen, P.A., Hensley, S. \& Chen, C, 2010. Measurement and mitigation of the ionosphere in L-band Interferometric SAR data, in Proceedings of the 2010 IEEE Radar Conference, pp. 1459-1463. doi:10.1109/radar.2010.5494385.

Samsonov, S.V., Lantz, T.C., Kokelj, S.V. \& Zhang, Y., 2015. Growth of a young pingo in the Canadian Arctic observed by RADARSAT-2 interferometric satellite radar, Cryosph. Discuss., 9, 6395-6421.

Short, N., Brisco, B., Couture, N., Pollard, W., Murnaghan, K. \& Budkewitsch, P., 2011. A comparison of TerraSAR-X, RADARSAT-2 and ALOS-PALSAR interferometry for monitoring permafrost environments, case study from Herschel Island, Canada, Remote Sens. Environ., 115, 3491-3506.

Smith, W.H.F. \& Sandwell, D.T., 1997. Global sea floor topography from satellite altimetry and ship depth soundings, Science (80-.), 277, 19561962.

Snyder, D.B., Roberts, B.J. \& Gordey, S.P., 2005. Contrasting seismic characteristics of three major faults in northwestern Canada, Can. J. Earth Sci., 42, 1223-1237.

Wegmüller, U. \& Werner, C., 1997. Gamma SAR processor and interferometry software, ESA SP 1687-1692.

Wessel, P. \& Smith, W.H.F., 1998. New, improved version of generic mapping tools released, EOS, Trans. Am. geophys. Un., 79, 579, doi:10.1029/98eo00426.

Wessel, P., Smith, W.H.F., Scharroo, R., Luis, J. \& Wobbe, F., 2013. Generic mapping tools: improved version released, EOS, Trans. Am. geophys. Un., 94, 409-410.

Yamamoto, T., Arikawa, Y., Ueda, Y., Itoh, H., Nishida, Y., Ukawa, S., Tsuru, H. \& Yamamoto, M., 2016. Autonomous precision orbit control considering observation planning: ALOS-2 flight results, J. Guid. Control. Dyn., 39, 1244-1264.

Yu, C., Li, Z. \& Penna, N.T., 2018. Interferometric synthetic aperture radar atmospheric correction using a GPS-based iterative tropospheric decomposition model, Remote Sens. Environ., 204, 109-121.

Yu, C., Penna, N.T. \& Li, Z., 2017. Generation of real-time mode highresolution water vapor fields from GPS observations, J. geophys. Res. Atmos., 122, 2008-2025.

Zebker, H.A., Rosen, P.A. \& Hensley, S., 1997. Atmospheric effects in interferometric synthetic aperture radar surface deformation and topographic maps, J. geophys. Res., 102, 7547-7563.

\section{SUPPORTING INFORMATION}

Supplementary data are available at $G J I$ online.

Figure S1. Coherence improvements after the subpixel offsets applied in the SLC resampling.

Figure S2. Uncertainties and trade-offs of eq. (1) uniform slip fault parameters computed using Monte Carlo analysis. At the bottom, histograms give uncertainties in the individual parameters. Scatterplots are degrees of trade-off between any two of these parameters. Figure S3. As Fig. S2, but for eq. (2).

Please note: Oxford University Press is not responsible for the content or functionality of any supporting materials supplied by the authors. Any queries (other than missing material) should be directed to the corresponding author for the article. 